\title{
CLASSE, RAÇA E A HISTÓRIA SOCIAL DO TRABALHO NO BRASIL (2001-2016)
}

Class, Race and the Social History of Labor in Brazil (2001-2016)

Clase, raza y la historia social del trabajo en Brasil (2001-2016)

\section{FABIANE POPINIGIS ${ }^{*}$}

PAUlo CRUZ TERrA ${ }^{\mathrm{II} * *}$

\footnotetext{
' Universidade Federal Rural do Rio de Janeiro (UFRRJ), Seropédica - RJ, Brasil.

*Professora adjunta do Programa de Pós-graduação em História do Departamento de História e Relações Internacionais da Universidade Federal Rural do Rio de Janeiro (PPGH/DHRI/UFRRJ), Seropédica - RJ, Brasil. (fpopinigis@gmail.com), ORCID iD: https://orcid.org/0000-0001-5218-0566

II Universidade Federal Fluminense (UFF), Niterói - RJ, Brasil.

* *Professor adjunto da Universidade Federal Fluminense (UFF), Niterói - RJ, Brasil. (pauloterra@gmail.com), ORCID iD: https://orcid.org/0000-0002-0717-3399

Artigo recebido em 15 de novembro de 2018 e aceito para publicação em 19 de fevereiro de 2019.
} 


\section{RESUMO}

Em artigo de 1998, Silvia H. Lara fez uma dura crítica à exclusão dos negros, escravos ou libertos, da história do trabalho no Brasil. Identificada somente com o trabalho livre e assalariado, esta teria ignorado as experiências e lutas daqueles trabalhadores antes e depois da abolição. Passados quase vinte anos da publicação desta crítica, bastante influente no meio acadêmico desde então, nosso objetivo aqui é retomar tal questionamento, buscando identificar como e em que medida a demanda por diálogos ampliados foi incorporada na produção do Grupo de Trabalho (GT) Mundos do Trabalho, ligado à Associação Nacional de História, e usando como fonte a produção apresentada por pesquisadores no âmbito do referido GT.

PALAVRAS-CHAVE: História do trabalho; Escravidão; Liberdade, GT Mundos do Trabalho.

\section{ABSTRACT}

In a 1998 article, Silvia H. Lara made a harsh critique regarding the exclusion of Black people, be them enslaved or free, from the history of labor in Brazil. Identified only with free and wage-earning labor, this history would have ignored the experiences and struggles of those workers before and after the abolition of slavery. Twenty years after the publication of this is critique, which has been highly influential among academia, our goal in the present article is to resume this questioning, trying to identify how and to what extent the demand for expanded dialogues was incorporated into the production of the Work Group Mundos do Trabalho ('Worlds of Labor'), which is connected to Associação Nacional de História ('National History Association'), and using as sources the production presented by the researches within this Work Group.

KEYWORDS: History of labor; Slavery; Freedom; Work Group Mundos do Trabalho.

\section{RESUMEN}

En un artículo de 1998, Silvia H. Lara hizo una dura crítica a la exclusión de los negros, esclavos o libertos, de la historia del trabajo en Brasil. Identificada solo con el trabajo libre y asalariado, esta tendría ignorado las experiencias y luchas de aquellos trabajadores antes y después de la abolición. Pasados casi veinte años de la publicación de esta crítica, muy influyente en el medio académico desde entonces, nuestro objetivo aquí es retomar tal cuestionamiento, buscando identificar como y en qué medida la demanda por diálogos ampliados fue incorporada en la producción del Grupo de Trabajo (GT) Mundos do Trabalho ("Mundos del Trabajo"), conectado a la Associação Nacional de História ("Asociación Nacional de Historia"), y usando como fuente la producción presentada por investigadores en el ámbito del referido GT.

PALABRAS CLAVE: História del trabajo; Esclavitud; Libertad; GT Mundos do Trabalho. 
E m 1998, Silvia H. Lara fez duras críticas à história do trabalho no Brasil. Segundo ela, a produção acadêmica até então teria excluído os negros, escravos ou libertos, daquela história, por identificá-la somente com o trabalho livre e assalariado, ignorando as experiências e lutas daqueles trabalhadores antes e depois da abolição. Para a autora, essa exclusão se devia a uma abordagem pouco histórica, que privilegiava grandes modelos explicativos e não levava em conta os negros, escravos e libertos, como agentes da própria história. Numa virada historiográfica de meados dos anos 1970, os trabalhadores passavam a ser tratados como sujeitos capazes de estratégia e ação. Referenciando autores hoje já clássicos, Lara constatava que um novo ator havia despontado na historiografia sobre a Primeira República na década de 1980, antes dominada por temas tradicionais da história política (militares, oligarquias, classes médias, industrialização): o movimento operário.

Isso aconteceu, entretanto, sem que fosse rompido o antigo silêncio sobre a ausência dos negros na história. Do ponto de vista metodológico, avaliava Lara, predominavam paradigmas explicativos e esquemas teóricos que utilizavam conceitos como "substituição" e "transição", que tendiam a ocupar o espaço em que deveria estar a explicação de processos históricos específicos, e, em alguns casos, tendia-se à generalização das pesquisas sobre a experiência das fazendas de café em São Paulo para o resto do Brasil.

Assim, para Lara, os historiadores do trabalho deveriam voltar-se para alguns dos temas que os historiadores da escravidão haviam explorado - como as revoltas escravas, os quilombos, as famílias e as tensões com a classe senhorial, as tensões dos momentos finais da escravidão, e histórias de vida de escravos e libertos, para realizar "análises cruzadas de relações raciais, étnicas e de classe" (ibidem), o que permitiria incorporar visões escravas da escravidão e da liberdade e as experiências dos libertos no período após a abolição, bem como as relações entre trabalhadores escravos, livres e libertos.

Publicado aqui na revista Estudos Históricos quase 20 anos depois, um artigo de Álvaro Pereira do Nascimento (2016) traçava diagnóstico semelhante, ao continuar a frisar que os historiadores que se dedicaram à investigação dos trabalhadores pobres e do movimento operário pouco se preocuparam em incluir categorias como cor e raça nesses estudos. Além dos longos anos que os separam, há outros elementos que diferenciam os dois artigos. Nossa intenção aqui não é fazer uma relação exaustiva entre eles, mas avaliar as reflexões que pautaram as agendas de muitos pesquisadores nesse nosso recorte nos últimos 15 anos.

Em primeiro lugar, o foco de Nascimento é a periodização do pós-abolição, ou a República. Embora inicialmente afirme que o período abordado no artigo será o das décadas finais da escravidão mais as cinco primeiras décadas republicanas, o autor se concentra na Primeira 
República, como se percebe ao longo do texto. Assim, se para Silvia Lara (1998: 37) os historiadores precisavam "voltar à segunda metade do século XIX, revisitar fazendas e fábricas, procurar por greves e outras manifestações reivindicatórias, buscar espaços de sociabilidade e convívio" com o objetivo de "desvendar os significados culturais e políticos de uma história americana cuja face muitas vezes se pretendeu ocultar" (ibidem: 38), Nascimento (2016: 60621) propõe 3 caminhos para o que chama de "uma história do negro na Primeira República": 1) que orientadores ampliem sua bibliografia obrigatória para romper "o muro de Berlim historiográfico" ; 2) que, inspirados na historiografia da escravidão, os pesquisadores ampliem o leque de fontes, tendo como norte a pergunta sobre a cor dos indivíduos; e 3) a utilização do cruzamento nominativo de fontes para acompanhar trajetórias.

Assim, embora o objetivo de ambos seja incorporar a experiência de homens e mulheres negros à história social do trabalho, enquanto Lara sugere que olhemos para trás, em busca da compreensão das formas de organização social e econômica dos escravos e libertos ainda durante a escravidão para seguir os rastros de sua influência nos movimentos dos anos iniciais da República, Nascimento reivindica que os pesquisadores se perguntem sobre a "cor" dos indivíduos no período do pós-abolição.

As diferenças nos pressupostos que inspiram as duas análises e as sugestões para superar a ausência da experiência dos trabalhadores negros na história aponta, a nosso ver, para o deslocamento do campo dos estudos de escravidão para o chamado pós-abolição ocorrido nos últimos anos. Mas a ênfase de Nascimento no período do pós-abolição, e a de Lara no período anterior, evidenciam, sobretudo, o resultado atingido pelos esforços dos historiadores que transitam entre a história social do trabalho e da escravidão para compreender os significados da liberdade para trabalhadores escravos, livres e libertos, a historicidade e a ampliação do conceito de trabalhador, e a diversidade das atividades realizadas por eles e elas no tempo e no espaço. Ou seja, uma parte do trabalho dos pesquisadores nessa pauta - a de superar a dicotomia entre trabalho escravo e trabalho livre, desassociar a periodização da história da ação dos trabalhadores do assalariamento e levar em conta as experiências de luta dos trabalhadores escravizados - tem estado consistentemente nas agendas de pesquisa, enquanto que a outra parte - sobre os efeitos do racismo no mercado de trabalho e as relações raciais na organização dos movimentos sociais, nos sindicatos e nos períodos mais adiantados da República - ainda precisa de estímulos consistentes.

Neste artigo, buscamos identificar como e em que medida a história do trabalho travou 0 diálogo com a historiografia da escravidão no intervalo entre o diagnóstico de Lara e o balanço de Nascimento a partir da produção apresentada pelos pesquisadores no âmbito do Grupo 
de Trabalho Mundos do Trabalho (GTMT), nos simpósios da Associação Nacional de História (Anpuh) entre 2001 e 2015, e nos seminários internacionais entre 2011 e 2016.

Assim, nosso interesse recai sobre as pesquisas que tratam: da diversidade de formas de exploração do trabalho que coexistiram como parte fundamental do desenvolvimento social e econômico do capitalismo, possibilitando experiências comuns entre os trabalhadores; de como as lutas e resistências desses indivíduos, escravizados e livres, influenciaram e moldaram seus movimentos organizativos tanto durante quanto após o fim da escravidão legal; e do lugar central das relações raciais nos mundos do trabalho, tanto em relação à formação de identidades, de redes de sociabilidades e rivalidades, quanto do racismo que configurou a formação do mercado de trabalho "livre" e se reproduziu ao longo de todo o século XX.

O GTMT não é o único espaço a abrigar pesquisadores que se interessam pelos estudos do trabalho e dos trabalhadores juridicamente livres ou escravizados. Nossa escolha se dá, entre outras razões, porque é neste âmbito, sobretudo, que se tem desenvolvido esforço sistemático de enfrentamento das questões levantadas em 1998 pelo artigo de Lara e retomado em outros artigos de balanço de membros do próprio GT (Negro; Gomes, 2006; Chalhoub; Silva, 2009; Nascimento, 2016).

\section{A ANPUH E O GTMT}

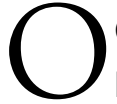

GTMT formou-se a partir da iniciativa de um grupo de professores pesquisadores do Rio Grande do Sul e outro de São Paulo, que, no ano 2000, propôs a criação de um grupo de trabalho nacional e sua oficialização à diretoria da Anpuh. Na esteira desta proposta, vários núcleos foram criados em outras regiões do País nos anos seguintes. ${ }^{1}$

A partir de então, o GTMT passou a organizar simpósios específicos sobre a história do trabalho dentro dos simpósios nacionais de história (SNHs) organizados pela Anpuh. Os SNHs são atualmente as maiores reuniões de historiadores no Brasil, realizadas bianualmente. ${ }^{2}$ Desde a sua criação, em 2000, o GTMT apresenta comunicações coordenadas (2001) e simpósios temáticos (a partir de 2003) nos SNHs da Anpuh.

Atualmente, existem 23 GTs dentro da Anpuh, entre eles alguns que dialogam mais estreitamente com os pesquisadores e temas apresentados no GT Mundos do Trabalho. São eles o GT Estudos de Gênero, o GT História da África e o GT de História dos Partidos, o GT Movimentos de Esquerda e especialmente o GT Pós-abolição e emancipações. ${ }^{3}$

O GTMT tem se proposto ser um espaço que reúne e promove discussões entre historiadores interessados na história do trabalho. Criado em 2000, além de ser um dos mais antigos 
em funcionamento, é o que reúne também na atualidade um dos maiores contingentes de pesquisadores no âmbito da Anpuh. ${ }^{4} 0$ grupo tem objetivado não restringir a sua atuação somente à Anpuh, procurando ampliá-la - por meio de encontros internacionais específicos e de uma revista própria - para demarcar uma posição na produção acadêmica brasileira atual e internacionalizar o diálogo e a produção de seus membros.

Para Marcel van der Linden (2009: 13), diretor de pesquisa do Instituto Internacional de História Social, a constituição do GTMT no Brasil esteve relacionada "a um 'retorno' à História do Trabalho e a um contexto de expansão dos estudos sobre os trabalhadores no Hemisfério Sul. Assim como no caso brasileiro, em 1995 foi fundada a Associação de Historiadores do Trabalho Indianos, e conferências nacionais ocorreram em Karachi (1999), Seul (2001), Jogjacarta (2005) e Joanesburgo (2006)". O GTMT teve papel central na introdução das agendas de novos temas, sujeitos e abordagens teórico-metodológicas que questionavam as construções eurocêntricas na produção historiográfica brasileira de uma "nova história do trabalho" e sua especificidade no contexto da América Latina (Fortes; French, 2013).

Desde a formulação original do GT, aparece a intenção "de abordar o mundo do trabalho a partir de diferentes enfoques, tais como organizações de trabalhadores, cotidianos, relações de gênero, relações interétnicas, processos e tecnologias de trabalho, relações entre trabalho livre e trabalho compulsório, identidades, correntes políticas, entre outros" (Loner, 2009a: 6). Argumentaremos aqui que a abordagem das relações entre trabalho livre e trabalho compulsório não se constituiu apenas em um projeto, mas esteve presente na prática desde o início das atividades do GT.

\section{DELIMITAÇÃO TEMÁTICA E METODOLOGIA}

ara esta pesquisa, abordamos as três principais atividades do GTMT: os simpósios espe-
cíficos sobre história do trabalho dentro dos SNHs ANPUH; os encontros internacionais do GT; e os números da revista Mundos do Trabalho. Para a investigação aqui apresentada, realizamos um levantamento dos resumos de todos os trabalhos apresentados nos simpósios coordenados pelo GT nas reuniões da Anpuh entre 2001 e 2015; dos encontros internacionais de 2002 a 2016; e dos artigos e resenhas da revista Mundos do Trabalho, desde a sua criação, em 2009, até 2016.5

Selecionamos palavras-chave que contemplassem as linhas expostas anteriormente, representando o cruzamento dos campos sujeitos às críticas apresentadas no início do texto: trabalho escravo e trabalho livre; trabalho indígena; escravos, libertos e livres; escravidão e 
imigração; cor e trabalho; raça e trabalho; escravos e libertos, trabalho, pós-abolição; trabalho, pós-emancipação; escravidão e liberdade; trabalhadores e racismo; racismo e trabalho; movimentos sociais, racismo; greve, cor; partidos, sindicatos, negros; negros, mercado de trabalho; e contratos de trabalho, condição jurídica trabalho dependente, cativo, forçado, assalariado.

\section{TRABALHOS APRESENTADOS NOS SNHS DE 2001 A 2015}

omo mencionado anteriormente, a partir de sua oficialização, em 2000, o GTMT passou a agregar comunicações na Anpuh, sob a rubrica do grupo. No evento de 2001, uma entre nove comunicações foi apresentada dentro das características que aqui nos interessam. ${ }^{6}$ Trata-se do estudo de Maria Cecília Velasco e Cruz (2001) sobre o sindicato dos estivadores no Rio de Janeiro e em Salvador, que investiga variáveis como as raízes escravas do operariado desses portos.

Do SNH seguinte, em 2003, participaram 23 GTs, coordenando um total de 80 simpósios. O GTMT organizou dois deles: "Trabalhadores do Brasil, entre a negociação e o conflito" e "Trabalhadores: memória, identidade e formação de classe". Houve um salto no número de trabalhos inscritos: de 75 trabalhos apresentados no total de coordenações apresentadas pelo GTMT, 17 (22,7\%) eram relacionados à questão do trabalho compulsório e à análise das especificidades do trabalho escravo. ${ }^{7}$ Nesse sentido, menciona-se, por exemplo, a comunicação de Alinnie Silvestre Moreira sobre a experiência dos africanos livres na Fábrica de Pólvora da Estrela, no período de 1830 a 1850, ou a de Álvaro Pereira do Nascimento (2003) acerca do trabalho compulsório no serviço militar. Ressalta-se também a presença de duas comunicações que tratam da trajetória de homens negros no século XIX. A primeira delas, de Maria das Graças de Andrade Leal (2003), abordou a participação de Manuel Querino nos movimentos abolicionista e trabalhista da Bahia. A outra foi apresentada por Regina Célia Lima Xavier (2003), que analisou as disputas em torno da memória sobre Tito de Camargo Andrade, africano liberto que faleceu em 1882. Por último, frisa-se a comunicação de José Antônio dos Santos (2003) a respeito de líderes operários e militantes do movimento negro em Pelotas, na primeira metade do século XX.

No SNH de 2005 participaram 13 GTs, e 83 simpósios temáticos foram organizados. 0 GTMT foi responsável por três deles: "Trabalhadores, culturas e instituições de classe"; " Lutas sociais urbanas e rurais"; e "Trabalho escravo, trabalho compulsório e trabalho livre". Nesse ano houve um novo salto no número de comunicações que tratavam das questões debatidas neste artigo, que chegaram a 23 entre as 78 apresentadas nos simpósios do GTMT, representando $29 \%$ do total. Os trabalhos inscritos abordaram, além das questões mencionadas 
anteriormente, também as formas de organização e mobilização dos trabalhadores livres e escravizados, bem como as experiências do pós-abolição. ${ }^{8}$

No Simpósio Nacional de 2007 foram inscritos 76 simpósios temáticos, dentre os quais o GTMT apresentou 2, um deles intitulado "Cultura, cotidiano e identidades" e outro intitulado "As fronteiras entre as diversas formas de coerção e os diversos caminhos para a liberdade". As comunicações relacionadas ao tema passaram a 13, num total de 76, ou seja, 17\%. ${ }^{9}$ Ressalta-se a análise dos trabalhadores negros no pós-1950, especificamente na comunicação de Camilo Buss Araújo (2007) sobre as várias formas de negociação entre esses trabalhadores, moradores do Morro da Caixa d'Água, e grupos políticos em Florianópolis.

O simpósio seguinte, realizado em 2009, representou o maior contingente de comunicações totais nos simpósios do GTMT: foram 28 comunicações de um total de 119, significando um percentual de $23,5 \%$ envolvendo os temas e objetos de pesquisa aqui tratados, sobretudo no simpósio temático "Entre a escravidão e o pós-emancipação". Os outros dois simpósios do GTMT foram "Organizações e lutas" e "Tradições e culturas". Nesse ano foram apresentadas, pela primeira vez, três comunicações sobre serviço doméstico num simpósio do GTMT.$^{10}$

Em 2011, o GT apresentou três simpósios temáticos: "As lutas dos trabalhadores em perspectiva histórica: experiências, processos, contextos"; "A reinvenção dos mundos"; e "Nação, experiências e identidades nas fronteiras do trabalho". De um total de 76 das comunicações inscritas para os simpósios do GTMT, 17 (22\%) correspondiam à perspectiva aqui analisada, sendo que pela primeira vez foi apresentada uma pesquisa tratando do trabalho indígena. ${ }^{11}$

Em 2013, entre os 75 trabalhos inscritos, 18 (24\%) tratavam das temáticas aqui analisadas. 0 GTMT organizou três simpósios: "Instituições e política, costumes e direitos"; " Trabalho escravo e trabalho livre: cultura, costumes e lutas"; e "Processos produtivos, condições de trabalho e formas de resistência dos trabalhadores." ${ }^{12}$ As pesquisas sobre serviço doméstico totalizaram cinco apresentações. ${ }^{13}$

Em 2015, foram inscritas 17 comunicações com esse perfil do total de 85 trabalhos inscritos nos simpósios organizados pelo GT. Houve duas comunicações sobre trabalho escravo contemporâneo, uma delas sob uma perspectiva de gênero. ${ }^{14}$ Outras comunicações abordavam a relação entre etnicidade e classe na primeira metade do século $X X$, ou a relação entre racismo e trabalhadores nas décadas de 1960 e 1970. Mas, assim como nos simpósios anteriores, a maioria das comunicações tratou mais diretamente da relação entre trabalho livre e trabalho escravo no século XIX.

A sensível diminuição no número de inscritos pode estar relacionada à criação do GT Emancipações e Pós-abolição, em 2013, e à ocorrência do simpósio "Gênero, História e o 
Mundo do Trabalho Doméstico", que agregou os pesquisadores e pesquisadoras trabalhando esse tema em perspectiva de gênero fora do âmbito do GTMT.

Finalmente, de um total de 657 comunicações do GTMT nos SNHs da Anpuh no período entre 2001 e 2015, o significativo número de 138 pesquisadores inscritos abordaram, em seus resumos, a relação entre trabalho livre e trabalho escravo, e também o tema do pós-abolição, perfazendo $20 \%$ do total. Constatamos aqui que, se ao longo dos anos houve diversificação nas abordagens sobre as diversas formas de exploração do trabalho envolvendo distintos sujeitos, condições jurídicas e relações, o interesse pelos trabalhadores escravos e libertos e suas lutas esteve sempre representado nas propostas de comunicação, em geral em simpósios específicos sobre a temática.

\section{JORNADAS NACIONAIS DE HISTÓRIA DO TRABALHO E SEMINÁRIOS INTERNACIONAIS MUNDOS DO TRABALHO (2010-2016)}

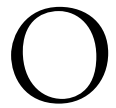

s seminários internacionais do GTMT, que passaram a existir em 2010 visando um aprofundamento do espaço de diálogo criaram um âmbito de trocas e debates com pesquisadores internacionais. Entre 2010 e 2014, do total de 617 comunicações apresentadas os quatro seminários internacionais, 121 (19,6\%) delas tratavam de temas que tangenciavam a relação entre as fronteiras do trabalho.

Em 2010, teve lugar o primeiro seminário internacional, na Universidade Federal de Santa Catarina (UFSC), em Florianópolis. A primeira sessão intitulava-se "Histórias do trabalho entre a escravidão e a liberdade", e teve comunicações de antigos membros do GTMT, como Beatriz Loner, que apresentou o trabalho intitulado "Experiências e vivências de ex-escravos urbanos na sociedade do trabalho livre: trajetórias (in)comuns (2010):15 e houve três comunicações inscritas sobre o serviço doméstico: uma de Tatiana Silva de Lima (2010), que tratou do Recife; uma de Cecilia Allemandi (2010), que falou de Buenos Aires; e uma análise comparativa entre Índia, Sri Lanka e Quênia. de Kalpagam Umamaheswaran (2010). Álvaro Pereira do Nascimento (2010) abordou a relação entre trabalho e ascensão social na Marinha de Guerra, no período de 1870 a 1910, a partir das relações raciais, e Rodrigo de Azevedo Weimer (2010) acompanhou a trajetória de uma família de descendentes de escravos que se deslocaram da antiga fazenda do Morro Alto, no pós-1930, para municípios como Porto Alegre e Osório. Neste evento, pesquisadores da África do Sul trouxeram à tona a questão da importância da análise da questão racial nos movimentos sociais e no mercado de trabalho em comunicações como a de Marcelle Dawson (2010), intitulada "Race, Class and Ideology 
in Social Movements: Exploring Past and Present Movements in South Africa", e a de Bridget Kenny (2010), "Servicing a Racial Regime: The Labour of South African White Women Shop Workers in Building a Nation, 1940s-1970s".

Em 2012, no II Seminário Internacional, realizado no Rio de Janeiro, na Fundação Getulio Vargas (FGV), 2 sessões foram inteiramente dedicadas à discussão da relação entre liberdade e escravidão: a primeira delas intitulou-se "Na transição para o trabalho livre: trabalhadores em trânsito", e a segunda, "Os significados da liberdade nas trajetórias de libertos: contratos de trabalho, educação e imprensa". As duas contaram com membros mais antigos do GTMT identificados com a temática, como Marcelo Badaró Mattos (2012), Maria Cecília Velasco e Cruz (2012) e Beatriz Ana Loner (2012) no caso da primeira sessão, e Álvaro Pereira do Nascimento (2012), Fabiane Popinigis (2012), Henrique Espada Lima (2012) e Marcelo Mac Cord (2012) no caso da segunda. A presença de pós-graduandas nas duas sessões indicava a renovação na área. As comunicações apresentadas abordaram elementos centrais levantadas por Lara (1998): por um lado, a discussão sobre os significados da "transição", e, por outro, a investigação de histórias de vida e trajetórias de libertos tanto durante a escravidão quanto após a abolição.

No mesmo evento, a discussão sobre o trabalho análogo à escravidão apareceu nas comunicações de Norberto O. Ferreras (2012) e Cristiana Costa da Rocha (2012); a comunicação de Maria Celma Borges "Escravos, roceiros e povos originários nos campos do sul de Mato Grosso (séculos XVIII e XIX)" (2012) abordou o tema do trabalho indígena; a questão racial foi debatida de forma mais detida por Sarah Calvi Amaral Silva em seu resumo sobre o II Congresso Afro-Brasileiro de Salvador (1937) em diálogo com o III Congresso Sul-Rio-Grandense de História e Geografia do Instituto Histórico e Geográfico do Rio Grande do Sul (IHGRS) (1940); e a temática do serviço doméstico teve aqui dois resumos de comunicações. ${ }^{16}$

Em 2014, realizou-se na Universidade do Estado da Bahia (Uneb), em Salvador, o III Seminário Internacional do GTMT. Duas sessões abordaram especificamente as relações raciais: a primeira delas intitulou-se "Experiências de escravidão e liberdade (Brasil, Cuba e EUA, séculos XIX e XX)", e reuniu comunicações como "Brazilian Toilet Luxuries: conversas transnacionais sobre raça, beleza e cosmética na imprensa negra pós-abolição do Brasil e dos EUA", de Giovana Xavier (2014), e "Disciplinarização do trabalho e discursos raciais em Cuba", de lacy Maia Mata (2014);17 a segunda sessão, por sua vez, intitulou-se "Raça e classe operária no Brasil", e teve, por exemplo, a comunicação de Petrônio Domingues (2014) sobre Minervino de Oliveira, um trabalhador negro comunista que disputou a presidência do Brasil pelo Bloco Operário e Camponês (BOC), nas eleições de 1930, e a discussão sobre a questão racial no debate político brasileiro em 1964, apresentada por Pedro Chadarevian. ${ }^{18}$ 
Nesse ano cresceu o número de apresentações de pesquisas sobre o serviço doméstico, que ocuparam duas sessões específicas ${ }^{19}$ e uma comunicação (Souza, F., 2014) em outra sessão, e cresceu também o número de comunicações sobre trabalho indígena, inseridas em duas sessões específicas sobre o trabalho na Amazônia: ${ }^{20}$ comunicações que traziam a convivência entre trabalhadores indígenas e africanos nessa região, como a de Patrícia Melo Sampaio, "Revisitando fronteiras: índios, africanos livres e escravos no Rio de Janeiro, Belém e Manaus no século XIX" (2014).

Em 2016, ocorreu em Manaus o IV Simpósio Internacional Mundos do Trabalho. Nesse evento, teve destaque o trabalho indígena, que, além de duas sessões específicas, ${ }^{21}$ foi tema uma mesa-redonda intitulada "Trabalho, indigenismo e história ambiental" e de vários resumos de comunicações.

Foram diversas as sessões coordenadas que conjugaram nos títulos e nos resumos os termos raça, a classe e etnicidade. Ressalta-se a presença de uma sessão sobre "Trabalho, Escravidão e Pós-Abolição", com comunicações de Ana Flávia Magalhaes Pinto (2016), Melina Perussato (2016), Kátia Almeida (2016) e Flavia Veras (2016), e outra sobre "Escravização llegal e Exploração do Trabalho no Século XIX", com comunicações de Keila Grinberg (2016), Beatriz Mamigonian (2016), Patrícia Sampaio (2016), e Antônia Pedroza (2016). As sessões "Raça e Etnicidade", "Sobre as Linhas Tortas da Liberdade: Raça, Classe e Etnicidade nos Limiares da Escravidão no Brasil", "Experiências e Luta por Liberdade" e "Raça, Imigração e Trabalho nas Américas" também fizeram parte do evento. Essas sessões coordenadas reuniram muitos pesquisadores que transitam nesses âmbitos de debate e são bons exemplos de diálogo entre temas de interesse dos estudiosos do pós-abolição e dos mundos do trabalho, ao associar e integrar abordagens de raça e classe.

Nos simpósios internacionais aqui analisados, é possível perceber também a diversidade regional dos pesquisadores e suas pesquisas, bem como uma tendência a ampliar as abordagens internacionais e as relações entre as diferentes localidades, regiões e países e a circulação de seus agentes, produtos, serviços e ideias.

\section{REVISTA MUNDOS DO TRABALHO}

o primeiro número da revista Mundos do Trabalho, Beatriz Loner (2009a: 6) apontou
como objetivo do periódico que ele "apresentasse nossas ideias, servisse para aprofundar o debate, normalmente presente em nossos simpósios e encontros, e que também auxiliasse a difundir a ideia da união de pesquisadores do trabalho num fórum único". A autora, 
que foi a primeira coordenadora do GT, percebia então "o lento, mas constante, processo de aproximação de pesquisadores que tratam do trabalho livre e assalariado, com aqueles que lidam com o trabalho coercitivo, principalmente com o trabalho escravo" (ibidem: 7).

Ainda no primeiro número, entre os 11 artigos presentes, há o escrito por Marcelo Badaró Mattos, intitulado "Trajetórias entre fronteiras: o fim da escravidão e o fazer-se da classe trabalhadora no Rio de Janeiro" (2009). No segundo número, também de 2009, além de um dos nove artigos contemplar a temática em perspectiva de gênero (Sbravati, 2009), duas das cinco resenhas (Loner, 2009b; Grosso, 2009) também o fizeram. As resenhas e os temas dos dossiês indicam decisões e estratégias do comitê editorial da revista, que passou a ser organizada por artigos dentro de um dossiê, além dos artigos com temática livre a partir do segundo número.

Dois dossiês nos interessam aqui particularmente por trazerem temáticas discutidas ao longo deste artigo. 0 primeiro deles, foi publicado no número 6, em 2011, se intitula "(Outros) Trabalhadores Livres no Atlântico Oitocentista", e ressalta a proximidade entre a liberdade jurídica e as formas de coerção do trabalho. 0 outro dossiê, intitula-se "Trabalho, Política e Experiências Indígenas", e foi publicado no número 12, em 2014. Entre os variados temas abordados nos artigos, além do trabalho indígena e da relação entre trabalho livre e trabalho coercitivo, estavam também presentes: trabalho doméstico, abolicionismo e trabalhadores, trabalhadores e trabalhadoras negras, identidades africanas, e pós-abolição.

Nos 16 números publicados até 2016, encontram-se 190 artigos, 23 (12\%) referentes aos temas mencionados anteriormente. Já as resenhas totalizaram 34, sendo $4(11,7 \%)$ relativas a eles. Percebe-se, portanto, uma presença menor de resultados de pesquisa relacionando trabalho, escravidão e liberdade nos mundos do trabalho no periódico do que nos simpósios da Anpuh e nos seminários internacionais do GT. Ainda assim, é possível constatar que há uma presença constante de textos publicados ligados a essas abordagens na revista.

\section{APONTAMENTOS FINAIS: DESAFIOS PARA A PRODUÇÃO HISTORIOGRÁFICA BRASILEIRA}

$\mathcal{Z}$ uscamos neste artigo fazer um levantamento preliminar com o intuito de compreender o
papel do GTMT em relação à agenda delineada por Silvia Lara em 1998, isto é, a incorporação das experiências de vida e trabalho e das lutas dos trabalhadores africanos e descendentes ao longo dos séculos no Brasil. Pudemos então perceber, pelos resumos das comunicações apresentadas nos simpósios do GTMT nos encontros da Anpuh nacional, bem como pelos resumos apresentados nos seminários internacionais promovidos pelo próprio GT e pelos artigos 
e resenhas publicados na revista Mundos do Trabalho, que houve um interesse constante por esse diálogo desde sua criação. Novas abordagens e temas surgiram ao longo desses anos a partir de pesquisas que incorporaram as experiências dos sujeitos, práticas e relações, tornando mais complexas as análises sobre os trabalhadores brasileiros e suas lutas, e iluminando a dependência do capitalismo de diversas e simultâneas formas de exploração do trabalho.

É o caso do crescimento do número pesquisas sobre serviço doméstico, o que revela tanto um diálogo com as questões do seu tempo quanto com o processo de ampliação do conceito de trabalho e de trabalhador no campo da história social do trabalho, pois envolve uma série de questões representativas da complexidade do debate, exigindo, em geral, análises que de fato integrem gênero, raça e classe. Se essas são categorias de análise para investigadores, trata-se de marcadores sociais de desigualdade mutuamente constitutivos nas experiências de vida e trabalho desses homens e mulheres que se sobrepõe de formas diversas em contextos históricos específicos.

Da mesma forma, as pesquisas tratando do trabalho de indígenas, africanos livres e do trabalho escravo contemporâneo têm sido fundamentais para superar a ideia de "transição" do trabalho escravo para o livre, como na crítica formulada por Lara. Essas pesquisas mostram que o predomínio do trabalho assalariado não se seguiu ao fim da escravidão, mas que houve uma diversificação de relações de trabalho compulsório, em que o trabalhador nacional prevalecia sobre o estrangeiro (Mamigonian, 2005: 392).

Assim, a vasta produção apresentada no âmbito ao GTMT mostra que este se tornou um importante espaço de estímulo para estudos e debates sobre as fronteiras entre escravidão e liberdade, raça e classe nos mundos do trabalho, o que nos permite retornar ao início deste artigo. À luz da grande diversidade e qualidade das pesquisas desenvolvidas e aqui citadas a partir deste levantamento, consideramos que é possível questionar a ideia de que os historiadores identificados com a História Social do Trabalho pouco dialogaram com especialistas em escravidão, ou que continuem a ignorar os trabalhadores negros.

Desde 2001, primeiro ano de participação do recém-criado GT na Anpuh nacional, os pesquisadores e pesquisadoras têm se dedicado a explorar as formas de organização e manifestação próprias das experiências dos cativos, ex-cativos e seus descendentes, bem como seus impactos na organização e manifestações dos trabalhadores no início do período republicano. Ressaltamos, entretanto, que é fundamental estimular e incorporar pesquisas sobre o impacto do racismo no mercado de trabalho e sobre as relações raciais na organização de partidos e sindicatos e nos movimentos sociais a partir de meados do século XX, temas e período para os quais essa abordagem tem sido pouco explorada. 
Constatamos, finalmente, que se as estratégias de organização dos simpósios e eventos têm destinado especial atenção à variedade das relações de trabalho e às lutas de trabalhadores negros escravizados, livres e libertos no século XIX e início do XX, como aponta este levantamento, ainda há pouco espaço nesses mesmos simpósios que estimulem pesquisas com perspectivas de gênero na história do trabalho, inclusive em seus temas mais clássicos. Não é por acaso que os dois artigos citados no início deste texto não tratam do tema, que é ignorado por Lara, e apenas tocado por Nascimento.

Assim, ainda que uma diversidade de sujeitos e formas de trabalho tenham sido incluídos pelas novas pesquisas, a incorporação da potencialidade analítica das reflexões feministas para as perspectivas de gênero ainda está por ser explorada. Ao longo de várias décadas, as abordagens feministas formularam críticas à dicotomia do trabalho "livre" e "não livre", argumentando que a ênfase no suposto avanço progressivo do trabalho assalariado e sua capacidade organizativa desconsiderava o papel fundamental do trabalho não remunerado na economia capitalista, e chamando a atenção para sua utilidade na definição dos papéis de gênero e na agenda de direitos (Frederici, 2012; Cobble, 2012).

Mesmo o trabalho de mulheres foi muito pouco abordado nas comunicações e pesquisas apresentadas nos seminários e não constituiu uma preocupação central do GT nas organizações dos simpósios temáticos desde sua fundação até 2015, como foi o caso das conexões entre trabalho escravo e trabalho livre. Além do dossiê "Perspectivas de Gênero nos Mundos do Trabalho", publicado na revista Mundos do Trabalho em 2009, ${ }^{22}$ um espaço importante para essa reflexão foi o simpósio temático intitulado "Mundos do Trabalho: Trabalho de Mulheres, Relações de Gênero e Organização Social" no último encontro da Anpuh ocorrido em 2017, que agregou um grande número de jovens pesquisadoras e pesquisadores. ${ }^{23}$

No seminário internacional ocorrido na Universidade Federal do Amazonas (Ufam) em 2016, na mesa "História Social do Trabalho: Gênero e Etnicidade" , uma das apresentações tratou do quantitativo de pesquisadoras que submetiam seus resumos nos eventos do grupo, em média a metade do total. Este número, no entanto, diminuía proporcionalmente nas posições de maior relevância e visibilidade das discussões, como as de palestrantes, debatedores e coordenadores, ou das estratégias organizativas como parte das comissões organizadoras e comissões científicas. ${ }^{24}$ Durante o debate, abordou-se a questão da representatividade dos pesquisadores negros no grupo. Consideramos, portanto, de fundamental importância que esses espaços sejam estimulados e ampliados por estratégias articuladas pelos membros do GT e suas coordenações regionais e nacional. 
Nesse sentido, os estudos sobre a Primeira República e o pós-abolição, por sua vez, presentes ao longo da década de 2000 nas discussões do GTMT e também fora dele, ganharam tanta força que se constituiu um GT na Anpuh que tem abrigado um grande número de comunicações em seus simpósios. ${ }^{25}$ Membros de longa data do GTMT estiveram presentes na fundação e nos simpósios e seminários do GT Emancipações e Pós-abolição. A pergunta sobre em que medida e em que termos as questões do GT pós-abolição se conectam com os problemas da história do trabalho se encontra aberta, e talvez mereça outro âmbito de reflexão. Embora esteja fora do escopo deste artigo, é importante citar que a mesa "Gênero, Raça e Classe na História Social do Trabalho", ocorrida em Porto Alegre em 2018, contou com a presença de uma das coordenadoras do GT Emancipações e Pós-abolição, Wlamyra Albuquerque, que enfrentou as questões deste diálogo e enfatizou sua importância. ${ }^{26}$

O GTMT, portanto, e os outros aqui nomeados no âmbito da Anpuh têm sido espaços privilegiados de articulação de pesquisadores, de compartilhamento da produção científica, e de debates acadêmicos e sobre o ensino de história. Tanto Lara quanto Nascimento defenderam a necessidade de estabelecer uma agenda para esses questionamentos fundamentais na compreensão dos significados das lutas por direitos e por cidadania que tiveram os negros como agentes e sua importância para a reflexão e ação nos dias de hoje. Torna-se urgente levar adiante e priorizar o debate sobre a história pública (Chalhoub; Fontes; 2009), o diálogo com a sociedade e os movimentos sociais, a escola e as comunidades, para a construção e circulação do conhecimento produzido, num momento de desafio à produção científica, às instituições democráticas e à própria universidade pública.

\section{NOTAS}

1 Atualmente há dez núcleos regionais, e cada um deles tem sua coordenação própria, articulada à coordenação nacional. Conferir essas e outras informações no site do GT Mundos do Trabalho: https://gtmundosdotrabalho.org/coordenacao-e-membros/.

2 Para ver a lista de simpósios e os links para os anais de cada um deles ver: http://site.anpuh.org/index.php/ quem-somos/simposio-nacional-de-historia.

3 Os outros GTs presentes na Anpuh são: GT Imagem, Cultura Visual e História; GT de História da Educação; GT Direitas, História e Memória; GT de História Cultural; GT História e Patrimônio Cultural; GT Os Índios na História; GT História Política; GT História dos Partidos e Movimentos de Esquerda; GT História, Direita e Autoritarismo; GT História das Religiões e das Religiosidades; GT História das Relações Internacionais; GT História da Saúde e das Doenças; GT História da Ciência e Tecnologia; GT História Contemporânea; GT História Antiga; GT Emancipações e Pós-abolição; GT de História Ambiental; GT de História da Infância e da Juventude; e GT de Ensino de História e Educação. Cf. http://site.anpuh.org/?lang=pt-br\#.Uz1m_05eSVU. 
4 No site do GT, encontravam-se, em 20 de outubro de 2017, 140 pessoas registradas como membros. Seus coordenadores foram, respectivamente Ana Beatriz Loner (Universidade Federal de Pelotas, UFPel), Alexandre Fortes (Universidade Federal Rural do Rio de Janeiro, UFRRJ), Marcelo Badaró Mattos (UFF), Henrique Espada Lima (Universidade Federal de Santa Catarina, UFSC), Paulo Ribeiro Fontes (Centro de Pesquisa e Documentação de História Contemporânea do Brasil da Fundação Getulio Vargas, CPDOC-FGV), Aldrin Castellucci (Universidade do Estado da Bahia, Uneb), César Augusto Bubolz (Universidade Federal do Amazonas, Ufam) e Clarice Gontarski Speranza (Universidade Federal do Rio Grande do Sul, UFRGS).

5 Esta pesquisa foi realizada até abril de 2017. Nesse sentido, não foram incluídos os dados referentes ao XXIX Simpósio Nacional de História, realizado em Brasília, em julho de 2017. Também não foram incluídos os números publicados após abril de 2017.

6 Cf. Associação Nacional de História (Anpuh). Anais do XXI Simpósio Nacional de História. Niterói: UFF, 2001. Disponível em: http://anais.anpuh.org/wp-content/uploads/ANPUH.S21.pdf.

7 Cf. Associação Nacional de História (Anpuh). Anais do XXI Simpósio Nacional de História. João Pessoa: s.n., 2003. Disponível em: http://anais.anpuh.org/wp-content/uploads/ANPUH.S22.R.pdf.

8 Cf. Associação Nacional de História (Anpuh). Anais do XXIII Simpósio Nacional de História. Londrina: s.n., 2005. Disponível em: http://anais.anpuh.org/wp-content/uploads/ANPUH.S23.R.pdf

9 Cf. Associação Nacional de História (Anpuh). Anais do XXIV Simpósio Nacional de História. São Leopoldo: Unisinos, 2007. Disponível em: http://anais.anpuh.org/wp-content/uploads/ANPUH.S24.R.pdf

10 cf. Lima (2009), Silva (2009), e Souza (2009).

11 Cf. Associação Nacional de História (Anpuh). Anais do XXVI Simpósio Nacional de História. São Paulo: USP, 2011. Disponível em: http://www.snh2011.anpuh.org/simposio/public.

12 Cf. Associação Nacional de História (Anpuh). Anais do XXVI Simpósio Nacional de História. Natal: UFRN, 2013. Disponivel em: http://www.snh2013.anpuh.org/simposio/view?ID_SIMPOSIO=1086.

13 Ver Barbosa (2013), Silva (2013), Sbravati (2013), Lima (2013), e Pereira (2013).

14 Ver Ferreras (2015) e Rocha (2015).

15 Os títulos e resumos das comunicações apresentadas no I Seminário Internacional encontram-se no site: http://labhstc.ufsc.br/eventos/historias-do-trabalho-no-sul-global.

16 Ver Souza (2012) e Garzoni (2012).

17 As outras comunicações foram de Robério Santos Souza (2014), e Álvaro Pereira do Nascimento (2014).

18 As outras comunicações foram de Loner (2014), Bongiovanni (2014), e Silva (2014).

19 As sessões são: "Trabalho doméstico em perspectiva: Brasil e Argentina no século XIX" e "Domestic Service in the Global South: a Historical Approach". Disponivel em: https://gtmundosdotrabalho.files.wordpress. com/2014/07/programac3a7c3a3o-completa.pdf.

20 As sessões são "Etnicidade e Trabalho na Amazônia"; e "Ocupação, Terra e Trabalho na Amazônia: 0 Caso do Pará. Disponível em: https://gtmundosdotrabalho.files.wordpress.com/2014/07/programac3a7c3a3o-completa.pdf . 
21 As sessões são: "Política Indigenista e Mundos do Trabalho na Amazônia" e "Migrações e Trabalho nas Terras e Águas da Amazônia (do Século XVIII ao XX)". Disponível em: https://gtmundosdotrabalho.files.wordpress.com/2016/03/cadernoderesumos-novopdf.pdf.

22 Cf. https://periodicos.ufsc.br/index.php/mundosdotrabalho/issue/view/1196.

23 Coordenado por Cristiana Schettini e Gláucia Fraccaro. A programação do simpósio temático da SNH XXIX, ocorrido na Universidade de Brasilia (UnB), está disponível em: http://www.snh2017.anpuh.org/simposio/view?ID_SIMPOSIO=120.

24 Apresentação de F. Popinigis: "A História do trabalho em perspectiva de gênero". Participaram da mesa redonda Maria Helena P.T. Machado e Benito Schmidt.

25 GT Emancipações e pós-abolição: https://emancipacoeseposabolicao.wordpress.com/2014/04/07/gt-emancipacoes-e-pos-abolicao-e-oficializado/.

26 A mesa, coordenada por Isabel Bilhão, contou também com a participação de Benito Schmidt e Gláucia Fraccaro, que abordaram temas como masculinidades entre militantes operários e as lutas das mulheres por direito no Brasil republicano.

\section{REFERÊNCIAS BIBLIOGRÁFICAS}

ALLEMANDI, Cecilia. "Muchacha se ofrece": Una reconstrucción del perfil del personal de servicio en la Ciudad de Buenos Aires a fines de siglo XIX y principios del XX. In: SEMINÁRIO INTERNACIONAL MUNDOS DO TRABALHO: HISTÓRIAS DO TRABALHO NO SUL GLOBAL, 1. 2010, Florianópolis. Anais... Florianópolis: UFSC, 2010.

ALMEIDA, Kátia Lorena Novais. Ocupação dos escravos e formação de pecúlio na área mineradora de Rio de Contas, Bahia - século XVIII. In: SEMINÁRIO INTERNACIONAL MUNDOS DO TRABALHO, 4. 2016, Manaus. Anais... Salvador: Ufam, 2016.

ARAÚJO, Camilo Buss. Políticas populistas em Florianópolis: cultura assistencial e sociabilidade no Morro da Caixa d'Água nos anos 1950". In: Associação Nacional de História (Anpuh). Anais do XXIV Simpósio Nacional de História. São Leopoldo: Unisinos, 2007. Disponível em: http://anais.anpuh.org/wp-content/uploads/ ANPUH.S24.R.pdf.

BARBOSA, Antônio. As trabalhadoras domésticas em Curralinho-BA: indícios da conquista de espaço de autonomia e liberdade nos últimos anos da escravidão, 1871- 1888. In: Associação Nacional de História (Anpuh). Anais do XXVII Simpósio Nacional de História. Natal: UFRN, 2013. Disponível em: http://www.snh2013. anpuh.org/simposio/view?ID_SIMPOSIO=1086.

BONGIOVANNI, Luca. "Grupo de animais curiosos" ou artistas de talento? As leituras racializadas das relações de trabalho no teatro ligeiro negro carioca (1926-1938). In: SEMINÁRIO INTERNACIONAL MUNDOS DO TRABALHO, 3. 2014, Salvador. Anais... Salvador: Uneb, 2014.

BORGES, Maria Celma. Escravos, roceiros e povos originários nos campos do sul de Mato Grosso (séculos XVIII e XIX). In: SEMINÁRIO INTERNACIONAL MUNDOS DO TRABALHO, 2. 2012, Rio de Janeiro. Anais... Rio de Janeiro: CPDOC-FGV, 2012. 
CHADAREVIAN, Pedro. A questão racial no debate político brasileiro em 1964. In: SEMINÁRIO INTERNACIONAL MUNDOS DO TRABALHO, 3. 2014, Salvador. Anais... Salvador: Uneb, 2014.

CHALHOUB, S.; SILVA, F.T. da. Sujeitos no imaginário acadêmico: escravos e trabalhadores na historiografia brasileira desde os anos 1980. Cadernos AEL, v. 14, n. 26, p. 14-47, 2009.

; FONTES, P. História Social do Trabalho, História Pública. Revista Perseu, v.3, n. 4, 2009.

COBBLE, D. S. The Promise and Peril of the New Global Labor History. International Labor and Working-Class History, n. 82, p. 99-107, outono 2012.

CRUZ, Maria Cecília Velasco e. A dialética da solidariedade e rivalidade: estivadores do Rio de Janeiro e Salvador. In: Associação Nacional de História (Anpuh). Anais do XXI Simpósio Nacional de História. Niterói: UFF, 2001. Disponível em: http://anais.anpuh.org/wp-content/uploads/ANPUH.S21.pdf.

. União dos Operários Estivadores: a luta por um sindicato nacional, 1903-1915. In: SEMINÁRIO INTERNACIONAL MUNDOS DO TRABALHO, 2. 2012, Rio de Janeiro. Anais... Rio de Janeiro: CPDCO-FGV, 2012.

DAWSON, Marcelle. Race, Class and Ideology in Social Movements: Exploring Past and Present Movements in South Africa. In: SEMINÁRIO INTERNACIONAL MUNDOS DO TRABALHO: HISTÓRIAS DO TRABALHO NO SUL GLOBAL, 1. 2010, Florianópolis. Anais... Florianópolis: UFSC, 2010.

DOMINGUES, Petrônio. Minervino de Oliveira: um negro comunista disputa a presidência do Brasil. In: SEMINÁRIO INTERNACIONAL MUNDOS DO TRABALHO, 3. 2014, Salvador. Anais... Salvador: Uneb, 2014.

FERRERAS, Norberto Osvaldo. Truck system. Os debates sobre o trabalho forçado contemporâneo na década de 1930 desde uma perspectiva latino americana. In: Associação Nacional de História (Anpuh). Anais do XXVIII Simpósio Nacional de História. Florianópolis: UFSC, 2015. Disponível em: http://www.snh2015.anpuh.org/.

. O Programa "Trabalho Decente" da OIT: Usos e aplicações por ONGs e organizações da sociedade civil. In: SEMINÁRIO INTERNACIONAL MUNDOS DO TRABALHO, 2. 2012, Rio de Janeiro. Anais... Rio de Janeiro: CPDCO-FGV, 2012.

FORTES, A.; FRENCH, J. Sobre encanadores e filósofos: fazendo história do trabalho no Brasil. In: et al; Cruzando fronteiras - novos olhares sobre a História do Trabalho. São Paulo: Fundação Perseu Abramo, 2013.

FREDERICl, S. Revolution at Point Zero: Housework, Reproduction, and Feminist Struggle. Nova York: P.M. Press, 2012.

GARZONI, Lerice de Castro. A Work to Be Learned: Changes in the Conception of 'Domestic Service' (Rio de Janeiro, Early Twentieth Century). In: SEMINÁRIO INTERNACIONAL MUNDOS DO TRABALHO, 2. 2012, Rio de Janeiro. Anais... Rio de Janeiro: CPDCO-FGV, 2012.

GRINBERG, Keila. Fugas, escravização ilegal e trabalho escravo na fronteira entre Brasil e Uruguai na década de 1850. In: SEMINÁRIO INTERNACIONAL MUNDOS DO TRABALHO, 4. 2016, Manaus. Anais... Salvador: Ufam, 2016.

GROSSO, Carlos Eduardo Millen. Entre dois mundos: senhores e escravos. História de um sacerdote africano na Bahia do século XIX. Mundos do Trabalho, v.1, n.2, p. 263-267, 2009.

KENNY, Bridget. Servicing a Racial Regime: The Labour of South African White Women Shop Workers in Building a Nation, 1940s-1970s. In: SEMINÁRIO INTERNACIONAL MUNDOS DO TRABALHO: HISTÓRIAS DO TRABALHO NO SUL GLOBAL, 1. 2010, Florianópolis. Anais... Florianópolis: UFSC, 2010. 
LARA, S. H. Escravidão, cidadania e história do trabalho no Brasil. Projeto História, São Paulo, n. 16, p. 25-38, fev. 1998.

LEAL, Maria das Graças de Andrade. Manuel Querino: pelo trabalho, para a liberdade. In: Associação Nacional de História (Anpuh). Anais do XXII Simpósio Nacional de História. João Pessoa: s.n., 2003. Disponível em: http://anais.anpuh.org/wp-content/uploads/ANPUH.S22.R.pdf.

LIMA, Henrique Espada. A liberdade como horizonte de expectativa: sobre os significados do pós-abolição antes que acontecesse. In: SEMINÁRIO INTERNACIONAL MUNDOS DO TRABALHO, 2. 2012, Rio de Janeiro. Anais... Rio de Janeiro: CPDCO-FGV, 2012.

LIMA, Tatiana Silva de. Significados do trabalho doméstico no Recife do século XIX. In: Associação Nacional de História (Anpuh). Anais do XXV Simpósio Nacional de História. Fortaleza: UFC, 2009. Disponível em: https:// anais.anpuh.org/?tag=s25.

. Resistências e sobrevivências dos trabalhadores domésticos e em domicílio, Recife, 1830 - 1870. In: Associação Nacional de História (Anpuh). Anais do XXVII Simpósio Nacional de História. Natal: UFRN, 2013. Disponível em: http://www.snh2013.anpuh.org/simposio/view?ID_SIMPOSIO=1086.

Crias da casa, domésticos e servos: interfaces dos mundos do trabalho no Recife de 1837 a 1870. In: SEMINÁRIO INTERNACIONAL MUNDOS DO TRABALHO: HISTÓRIAS DO TRABALHO NO SUL GLOBAL, 1. 2010, Florianópolis. Anais... Florianópolis: UFSC, 2010.

LINDEN, M. Van Der; História do trabalho: o velho, o novo e o global. Mundos do Trabalho, v.1, n. 1, p. 11-26, 2009.

LONER, Beatriz Ana. Apresentação. Mundos do Trabalho, v.1, n.1, p. 1-10, 2009a.

Sobre greves, revoltas, negociações e acomodação em busca da cidadania; negros na América Latina. Mundos do Trabalho, v.1, n. 2, p. 286-291, 2009b.

Experiências e vivências de ex-escravos urbanos na sociedade do trabalho livre: trajetórias (in) comuns. In: SEMINÁRIO INTERNACIONAL MUNDOS DO TRABALHO: HISTÓRIAS DO TRABALHO NO SUL GLOBAL, 1. 2010, Florianópolis. Anais... Florianópolis: UFSC, 2010. Disponível em: http://labhstc.ufsc.br/files/2012/09/Beatriz-Loner.pdf.

Justo e Giovanni: dois mestres sapateiros. In: SEMINÁRIO INTERNACIONAL MUNDOS DO TRABALHO, 2. 2012, Rio de Janeiro. Anais... Rio de Janeiro: CPDCO-FGV, 2012.

Anarquismo e afrodescendentes. In: SEMINÁRIO INTERNACIONAL MUNDOS DO TRABALHO, 3. 2014, Salvador. Anais... Salvador: Uneb, 2014.

MAC CORD, Marcelo. Operários e artífices organizados e sua luta pela jornada de oito horas. Recife, 18901891. In: SEMINÁRIO INTERNACIONAL MUNDOS DO TRABALHO, 2. 2012, Rio de Janeiro. Anais... Rio de Janeiro: CPDCO-FGV, 2012.

MAMIGONIAN, Beatriz. Revisitando a "transição para o trabalho livre": a experiência dos africanos livres. In: FLORENTINO, Manolo. Tráfico, cativeiro e liberdade. Rio de Janeiro: Civilização Brasileira, 2005.

A escravização ilegal de africanos e a reprodução do trabalho compulsório no Brasil oitocentista. In: SEMINÁRIO INTERNACIONAL MUNDOS DO TRABALHO, 4. 2016, Manaus. Anais... Salvador: Ufam, 2016.

; POPINIGIS, Fabiane (org.). Dossiê (Outros) Trabalhadores Livres no Atlântico Oitocentista. Mundos do Trabalho, v. 3, n. 6, 2011. 
MATA, lacy Maia Mata. Disciplinarização do trabalho e discursos raciais em Cuba. In: SEMINÁRIO INTERNACIONAL MUNDOS DO TRABALHO, 3. 2014, Salvador. Anais... Salvador: Uneb, 2014.

MATTOS, Marcelo Badaró. Abolicionismo e ação coletiva da classe trabalhadora: um olhar para além do nacional a partir do Brasil. In: SEMINÁRIO INTERNACIONAL MUNDOS DO TRABALHO, 2. 2012, Rio de Janeiro. Anais... Rio de Janeiro: CPDCO-FGV, 2012.

. Trajetórias entre fronteiras: o fim da escravidão e o fazer-se da classe trabalhadora no Rio de Janeiro. Mundos do Trabalho, v.1, n.1, p. 51-64, 2009.

MOREIRA, Vânia Maria Losada; JONG, Ingrid de; POPINIGIS, Fabiane (org.). Dossiê Trabalho, Política e Experiências Indígenas. Mundos do Trabalho, v. 6, n. 12, 2014.

NASCIMENTO, Álvaro Pereira do. Trabalhadores negros e o "paradigma da ausência": contribuições à história social do trabalho no Brasil. Estudos Históricos, v. 29, n. 59, p. 607-626, set.-dez. 2016.

Procurando definições: o trabalho compulsório no serviço militar. In: Associação Nacional de História (Anpuh). Anais do XXII Simpósio Nacional de História. João Pessoa: s.n., 2003. Disponível em: http://anais. anpuh.org/wp-content/uploads/ANPUH.S22.R.pdf.

. Trabalho e ascensão social na Marinha de Guerra (1870-1910). In: SEMINÁRIO INTERNACIONAL MUNDOS DO TRABALHO: HISTÓRIAS DO TRABALHO NO SUL GLOBAL, 1. 2010, Florianópolis. Anais... Florianópolis: UFSC, 2010.

. A educação e o caminho da liberdade: Silvino Azeredo e a educação dos egressos do cativeiro. In: SEMINÁRIO INTERNACIONAL MUNDOS DO TRABALHO, 2. 2012, Rio de Janeiro. Anais... Rio de Janeiro: CPDCO-FGV, 2012.

. De trabalhador a empreendedor: terras e citricultura em Nova Iguaçu (1880-1920). In: SEMINÁRIO INTERNACIONAL MUNDOS DO TRABALHO, 3. 2014, Salvador. Anais... Salvador: Uneb, 2014.

NEGRO, A. L.; GOMES, F. Além de senzalas e fábricas: uma história social do trabalho. Revista Tempo Social, v. 18, n. 1, p. 217-240, 2006.

PEDROZA, Antônia Márcia Nogueira. Relações de trabalho que podem levar ao cativeiro: escravização ilegal na província do Ceará no século XIX. In: SEMINÁRIO INTERNACIONAL MUNDOS DO TRABALHO, 4. 2016, Manaus. Anais... Salvador: Ufam, 2016.

PEREIRA, Viviane Barbosa. "Corpos e sensações distantes do ideal": cotidiano e trabalho de mulheres pobres na cidade do Recife no início da República". In: Associação Nacional de História (Anpuh). Anais do XXVII Simpósio Nacional de História. Natal: UFRN, 2013. Disponível em: http://www.snh2013.anpuh.org/simposio/ view?ID_SIMPOSIO=1086.

PERUSSATO, Melina. "Esclarecendo nossos cérebros e aplicando ao trabalho os resultados de nossos esforços intelectuais e materiais": trabalho e instrução no pós-abolição em Porto Alegre. In: SEMINÁRIO INTERNACIONAL MUNDOS DO TRABALHO, 4. 2016, Manaus. Anais... Salvador: Ufam, 2016.

PINTO, Ana Flávia Magalhaes. Vicente de Souza, homem de cor e homem universal: posicionamentos sobre raça na trajetória de um abolicionista, republicano e socialista negro no final do século XIX. In: SEMINÁRIO INTERNACIONAL MUNDOS DO TRABALHO, 4. 2016, Manaus. Anais... Salvador: Ufam, 2016.

POPINIGIS, Fabiane. Negociação escrava e estratégia senhorial nos últimos anos da escravidão. In: SEMINÁRIO INTERNACIONAL MUNDOS DO TRABALHO, 2. 2012, Rio de Janeiro. Anais... Rio de Janeiro: CPDCO-FGV, 2012. 
ROCHA, Cristiana Costa da. Trabalho análogo à escravidão: reflexões sobre os usos e apropriação do seguro-desemprego. In: SEMINÁRIO INTERNACIONAL MUNDOS DO TRABALHO, 2. 2012, Rio de Janeiro. Anais... Rio de Janeiro: CPDCO-FGV, 2012.

Parceiras na viagem: visões e versões femininas sobre migrações temporárias e trabalho escravo contemporâneo. In: Associação Nacional de História (Anpuh). Anais do XXVIII Simpósio Nacional de História. Florianópolis: UFSC, 2015. Disponivel em: http://www.snh2015.anpuh.org/.

SAMPAIO, Patrícia Melo. Revisitando fronteiras: índios, africanos livres e escravos no Rio de Janeiro, Belém e Manaus no século XIX. In: SEMINÁRIO INTERNACIONAL MUNDOS DO TRABALHO, 3. 2014, Salvador. Anais... Salvador: Uneb, 2014.

Índios e africanos livres no Arsenal de Marinha do Rio de Janeiro: dimensões do trabalho forçado no Brasil do XIX. In: SEMINÁRIO INTERNACIONAL MUNDOS DO TRABALHO, 4. 2016, Manaus. Anais... Salvador: Ufam, 2016.

SANTOS, José Antônio dos. Trabalhadores e movimento negro: negociação e conflito no Sul do Brasil. In: Associação Nacional de História (Anpuh). Anais do XXII Simpósio Nacional de História. João Pessoa: s.n., 2003. Disponível em: http://anais.anpuh.org/wp-content/uploads/ANPUH.S22.R.pdf.

SBRAVATI, Daniela. Os sentidos da liberdade: as libertas e o trabalho doméstico na freguesia de Desterro de 1870 a 1920. In: Associação Nacional de História (Anpuh). Anais do XXVII Simpósio Nacional de História. Natal: UFRN, 2013. Disponível em: http://www.snh2013.anpuh.org/simposio/view?ID_SIMPOSIO=1086.

Mulheres de (in)certa condição. Mundos do Trabalho, v.1, n.2, p. 13-40, 2009.

SILVA, Fernanda Oliveira da. Raça, Estado e racialização na história do trabalho. In: SEMINÁRIO INTERNACIONAL MUNDOS DO TRABALHO, 3. 2014, Salvador. Anais... Salvador: Uneb, 2014.

SILVA, Maciel Henrique. Trabalho, gênero e raça: escravas domésticas e outras criadas na literatura baiana e pernambucana In: Associação Nacional de História (Anpuh). Anais do XXV Simpósio Nacional de História. Fortaleza: UFC, 2009. Disponível em: https://anais.anpuh.org/?tag=s25.

Qual queda, esta menina foi forçada: solidariedades e narrativas populares entre trabalhadoras domésticas (Salvador, 1900). In: Associação Nacional de História (Anpuh). Anais do XXVII Simpósio Nacional de História. Natal: UFRN, 2013. Disponível em: http://www.snh2013.anpuh.org/simposio/view?ID_SIMPO$\mathrm{SIO}=1086$.

SILVA, Sarah Calvi Amaral . Trabalhadores e relações raciais na historiografia e nas ciências sociais brasileiras dos anos 30 e 40. In: SEMINÁRIO INTERNACIONAL MUNDOS DO TRABALHO, 2. 2012, Rio de Janeiro. Anais... Rio de Janeiro: CPDCO-FGV, 2012.

SOUZA, Flavia Fernandes de. Empregam-se todos os que precisam trabalhar: o serviço doméstico e o mundo do trabalho na cidade do Rio de Janeiro no final do século XIX. In: Associação Nacional de História (Anpuh). Anais do XXV Simpósio Nacional de História. Fortaleza: UFC, 2009. Disponível em: https://anais.anpuh.org/?tag=s25.

Entre a escravidão e a liberdade: os criados domésticos e o mundo do trabalho na cidade do Rio de Janeiro no final do século XIX. In: SEMINÁRIO INTERNACIONAL MUNDOS DO TRABALHO, 2. 2012, Rio de Janeiro. Anais... Rio de Janeiro: CPDCO-FGV, 2012. 
SOUZA, Flavia Fernandes de. Trabalho doméstico: considerações sobre um tema recente de estudos na História Social do Trabalho no Brasil. In: SEMINÁRIO INTERNACIONAL MUNDOS DO TRABALHO, 3. 2014, Salvador. Anais... Salvador: Uneb, 2014.

SOUZA, Robério Santos. Condições de trabalho dos trabalhadores nacionais e ofensas raciais na ferrovia da Bahia. In: SEMINÁRIO INTERNACIONAL MUNDOS DO TRABALHO, 3. 2014, Salvador. Anais... Salvador: Uneb, 2014.

UMAMAHESWARAN, Kalpagam. Colonial Governmentality and Domestic Labour: A Comparative Analysis of India, Sri Lanka and Kenya. In: SEMINÁRIO INTERNACIONAL MUNDOS DO TRABALHO: HISTÓRIAS DO TRABALHO NO SUL GLOBAL, 1. 2010, Florianópolis. Anais... Florianópolis: UFSC, 2010.

VERAS, Flávia Ribeiro. Artistas em preto e branco: os contratos artísticos internacionais a exclusão do negro da identidade nacional brasileira e argentina nas décadas de 1930 e 1940. In: SEMINÁRIO INTERNACIONAL MUNDOS DO TRABALHO, 4. 2016, Manaus. Anais... Salvador: Ufam, 2016.

XAVIER, Giovana. Brazilian Toilet Luxuries: conversas transnacionais sobre raça, beleza e cosmética na imprensa negra pós-abolição do Brasil e dos EUA. In: SEMINÁRIO INTERNACIONAL MUNDOS DO TRABALHO, 3. 2014, Salvador. Anais... Salvador: Uneb, 2014.

XAVIER, Regina Célia Lima. Um "bom trabalhador": disputas em torno da construção da memória. In: Associação Nacional de História (Anpuh). Anais do XXII Simpósio Nacional de História. João Pessoa: s.n., 2003. Disponível em: http://anais.anpuh.org/wp-content/uploads/ANPUH.S22.R.pdf.

WEIMER, Rodrigo de Azevedo. Vou-me embora, que eu vou trabalhar com meus direitos, porque um dia eu posso me aposentar. In: SEMINÁRIO INTERNACIONAL MUNDOS DO TRABALHO: HISTÓRIAS DO TRABALHO NO SUL GLOBAL, 1. 2010, Florianópolis. Anais... Florianópolis: UFSC, 2010. 